\title{
Acute exposure to 50-Hz magnetic fields increases Interleukin-6 in young
}

\section{healthy men.}

Brahim Selmaoui $^{1,2}$, Jacques Lambrozo ${ }^{3}$, Linda Sackett-Lundeen ${ }^{4}$, Erhard Haus ${ }^{4}$, Yvan Touitou $^{2}$

${ }^{1}$ Department of Experimental Toxicology, INERIS, Parc ALATA - BP2, 60550 Verneuil-enHalatte, France

${ }^{2}$ Unité de Chronobiologie, Fondation Ophtalmologique A. de Rothschild, 29 rue Manin, 75019-Paris, France

${ }^{3}$ EDF-Medical Studies Department 45 rue Kléber, 92000 Levallois, France

${ }^{4}$ University of Minnesota Medical School, HealthPartners Medical Group, Regions Hospital, St. Paul, Minnesota, 55101 USA

\section{Running head: Magnetic field and cytokines evaluation}

To whom correspondence should be addressed: (1) Brahim Selmaoui

Phone: $+33-(0) 3.44 .55 .82 .68$

Fax: +33-(0)3.44.55.68.00

E-mail: brahim.selmaoui@ineris.fr 


\section{Abstract}

Some epidemiologic studies have suggested that extremely low frequency magnetic fields might affect human health, and, in particular, that the incidence of certain types of cancer might increase among individuals living or working in environments exposed to such fields. This study is part of a broad study we conducted in humans. The study presented here was designed to look for possible effects of acute exposure to $50-\mathrm{Hz}$ magnetic fields $(10 \mu \mathrm{T})$ on the interleukin 1 beta (IL-1 $\beta$ ), interleukin 2 (IL-2), interleukin 6 (IL-6), interleukin-1 receptor antagonist (IL-1RA), and the interleukin-2 receptor (IL-2R) production. Thirty-two young men (20-30 years old) were divided into two groups (sham-exposed or control group, and exposed group) of 16 subjects each. All subjects participated in two 24-hour experiments to evaluate the effects of both continuous and intermittent (one hour "off" and one hour "on" with the field switched "on" and "off" every 15 seconds) exposure to linearly polarized magnetic fields. The subjects were exposed to the magnetic field from 2300 to 0800 while recumbent. Blood samples were collected during each session at 11:00, 17:00, 22:00, 01:00, 04:00, 06:00 and 08:00. Results showed that exposure to 50-Hz magnetic fields $(10 \mu \mathrm{T})$ significantly increases IL-6 when subjects were exposed to an intermittently magnetic field. However no effect has been observed on interleukin IL-1 $\beta$, IL-2, IL-1RA, and IL-2R.

Key words: Cytokines, Magnetic Field. 


\section{Introduction}

It is well known that overhead transmission lines, transformers, and household appliances are major sources of electromagnetic field (EMF) exposure. For this reason a concern regarding the potential effect of extremely low frequency magnetic fields (ELF-EMF) on human health has been widely debated, the main concerns focusing on their carcinogenic potential and relationship with immune system functions. This debate was stimulated by some epidemiological studies suggesting that exposure to $50-60 \mathrm{~Hz}$ MFs may be associated with an increased incidence of various types of cancer (1-11).

As the immune system is involved in the control of cancer development and other diseases, it is important to know whether or not immunological functions are affected by the exposure to ELF-MF. Several studies have examined various immune cell parameters but with conflicting findings. ELF-MF were reported to produce changes in the activity or the number of circulating natural killer (NK) cells (12-17). However, no changes were observed in other studies (18-22).

Cytokines which are produced by a variety of cells were also investigated. Exposure to low frequency pulsed electromagnetic fields increased interleukin-1 and interleukin-6 production by human peripheral blood mononuclear cells (23). It has been shown that exposure to $50 \mathrm{~Hz}$ sinusoidal MFs decreased TNF- $\alpha$ production, while no effect was found on IFN- $\gamma$ production (24). Another study has also reported that $50 \mathrm{~Hz}$ electromagnetic fields decreased TNF- $\alpha$ and IFN- $\gamma$ production and increased IL-1 $\beta$ production (25). It is to note that all these studies on cytokine production have been conducted in vitro. Overall, the possible effects of ELF magnetic fields have been investigated in different types of cell cultures. On the other hand, there are only a limited number of human studies that are dedicated to the investigation of effects of ELF on the immune system. The study presented here was designed to look for 
possible effects of acute exposure to $50-\mathrm{Hz}$ magnetic fields $(10 \mu \mathrm{T})$ on the IL-1 $\beta$, IL-2, IL-6, IL-1RA, IL-2R production in humans. 


\section{Materials and Methods}

\section{Human subjects}

Thirty-two healthy subjects volunteered for this study and provided written consent. All were men aged 20 to 30 years. They were selected after routine clinical and laboratory examinations. Selection criteria included: regular sleep habits, no medication, no chronic disease or disability, no recent acute illness, no smoking. Those selected were instructed to eat balanced meals and to abstain from consuming alcohol and coffee for 24 hours before and during each experimental session. They were synchronized with a diurnal activity from 08:00 to $23: 00$ and nocturnal rest.

\section{Exposure facility}

The experimental unit consisted of three independent rooms and a shared bathroom. The exposed subjects slept in the first room ( 2 beds), and the sham-exposed in the second ( 2 beds). We did not inform subjects of their exposure status. The wooden beds were arranged parallel to each other in each room. Before setting up the exposure materials and beds, we used "Linda Wheel and EMDEX II dosimetry systems" to evaluate the noise of the background magnetic field. Its' level was less than 40 nanotesla in both bedrooms. In the area immediately surrounding the experimental site, the flux density of the geomagnetic field was approximately $46 \mu \mathrm{T}$. Since a minimum distance of $6 \mathrm{~m}$ between exposed and sham-exposed beds is required to prevent the generated field from affecting the sham-exposed group, we spaced them $7 \mathrm{~m}$ apart. The devices for generation, calibration, and continuous monitoring of the magnetic field were located in the third room (26). 


\section{Magnetic field generation}

A linearly polarized magnetic field $(10 \mu \mathrm{T})$ was generated by a system based on Helmholtz coils. Three rectangular coils $(120$ x $140 \mathrm{~cm})$ spaced $80 \mathrm{~cm}$ apart were used for each bed. They were wrapped in wood and look like normal wooden stems attached to the bed and allowed subjects to feel comfortable towards the device. The coils were positioned at the level of the head, groin and ankles. When energized the coils did not produce any vibration. The device was able to generate both continuous and intermittent exposure conditions. In the intermittent exposure, the device was turned "on" for one hour and "off" for the next hour. Whenever the device was turned "on", the magnetic field was on a 15-second "on-off" cycle. Since "on-off" switching operations induce high frequency transient electric fields that can have a biological effect, the signal generator was monitored by computer and synchronized with passages at zero of the current wave to avoid any transient fields. The magnetic field was generated by a Tollner generator and amplified by a Kepco amplifier, all under a computer controled system developed by Electricité de France, Research and Development Department engineers. A "Positron" dosimeter system was attached to the subject's body at the height of the pelvis, to control the exposure quality and to verify that the device was working. The 10 $\mu \mathrm{T}$ intensity was chosen as representative of the average level of exposure in occupational settings or near transmission lines for electrical workers after a dosimetry survey.

\section{Experimental procedure}

This experiment studied four subjects per day ( 2 exposed and 2 sham exposed), and each subject participated in three 24-hour sessions. They arrived at the laboratory at 09:30. Catheters were placed in antecubital vein for the 24-hour period, and the first blood sample was obtained at 11:00. They slept in darkness between 23:00 and 08:00 and spent their waking time in the laboratory (diurnal activity from 08:00 to 23:00 and nocturnal rest). Blood 
samples (tubes without anticoagulant) were taken from 11:00 to 08:00 of the following day (11:00, 17:00, 22:00, 01:00, 04:00, 08:00). During the day, 15 minutes before each sampling, subjects were asked to lie down in semi recumbent position until sampling time. From 01:00 to 08:00, the samples were obtained under dim light (less than 50 Lux) without waking the subjects, who slept with eye-mask from 23:00 to 08:00. Exposure to magnetic field lasted from 23:00 until 08:00.

The first $24 \mathrm{~h}$ session was performed before starting the experiment and leads subjects to be acclimated to the environment and devices.. We studied two groups: the first, sham-exposed, i.e., control $(\mathrm{N}=12-16)$, and the other, exposed $(\mathrm{N}=12-16)$. During the second session, two weeks after the first, a continuous $50-\mathrm{Hz}$ magnetic field of $10 \mu \mathrm{T}$ was applied. In the third session, a month after the second, the same subjects previously exposed to a continuous magnetic field were exposed to an intermittent $50-\mathrm{Hz}$ magnetic field of $10 \mu \mathrm{T}$. The same subjects served as sham contols in both sessions. No one has reported an auditory or tactile cue that could be produced by the coils when energized. This protocol was approved by the local ethics committee.

\section{Cytokine assay}

IL-1RA (R\&D System, Minneapolis, MN, USA), IL-2R (Genzyme Corporation, Cambridge, MA, USA), IL-1 $\beta$, IL-2, IL-6 (Biosource, Europe S.A., Fleurus Belgium), were assayed by ELISA in duplicate using serum samples drawn during the two $24 \mathrm{~h}$ study days. Sampling occurred at 11:00, 17:00, 22:00, 01:00, 04:00, 06:00, and 08:00. For inter- assay coefficients of variation (see Table I).

\section{Statistical analysis}


The data are expressed as means \pm SEM. Data were analyzed with 2- way ANOVA repeatedmeasures (GraphPad v5.02). The main effects of field, time factor and their interaction were tested (Table 2). Post-test Bonferroni was applied. The significance level was set at $\mathrm{p}<0.05$. 


\section{Results}

Significant changes in the concentration of IL-6 were observed in the subjects exposed to intermittent MF. Bonferroni post-tests analysis showed an elevation in serum IL-6 was statistically significant at 06:00 and 08:00 with $\mathrm{p}<0.01$. However, exposure to continuous or intermittent magnetic fields of $10 \mu \mathrm{T}$ did not affect or modify the cytokine production levels of IL-1 $\beta$, IL-2, IL-1RA or IL-2R. No significant interaction between the field and the time of sampling was found (Table II). There was also no statistical significance of the main effects of the field (Table II). Data are presented in Figures 1 and 2. 


\section{Discussion}

Epidemiological studies have shown an association between ELF exposure above approximately 0.3-0.4 $\mu \mathrm{T}$ and an increased risk of childhood leukemia (27, 28). However, despite several years of work, evidence from experimental studies to support a causal relationship between ELF exposure and leukemia is lacking and argues against causality. Thus ELF-MF exposure continues to generate a debate about its possible effects on health. In addition, there is no identified mechanism by which ELF-MF exposure in doses below $5 \mu \mathrm{T}$ might affect the incidence of cancer or any other disease in the human population (29). As the immune system is involved in several types of cancers it is worthwhile to explore the effect of ELF-MF exposure on the immune system.

Our present controlled study was conducted in humans who were exposed for one night to $50 \mathrm{~Hz}$ MF of $10 \mu \mathrm{T}$ from 23:00 to 08:00. Results showed that IL-6 production significantly increased in subjects exposed to intermittent but not with continuous exposure. Bonferroni post test showed that the significance is more observed in the last part of the night (06:00 and 08:00). Since IL-6 shows a circadian rhythm with peak in the morning hours (30), the data presented may suggest a circadian stage depending stimulation of IL-6 production by the intermittent MF. The increase of IL-6 production during that time was approximately 4 to 5 fold higher than control group. Even if non-significant, the upward trend for IL-6 was observed from 01:00 just after the onset of exposure time (23:00). IL-6 is a cytokine secreted predominantly by T-cells and macrophages with both pro- and anti-inflammatory effects. IL6 stimulates the immune response to trauma and other tissue damage leading to inflammation (31). Its role as an anti-inflammatory cytokine is mediated through its inhibitory effects on tumor necrosis factor alpha (TNF $\alpha)$ and IL-1 and activation of IL-1 RA and IL-10. IL-6 is a regulator of body temperature and fever and mediator of the acute phase response (32). It 
crosses the blood brain barrier and plays a role in neuroinflammation and some types of dementia (33). IL-6 is relevant to many disease processes such as diabetes (34), atherosclerosis (35), depression (36), autoimmune diseases (37, 38, 39), and some forms of cancer (40, 41, 42, 43). High levels of IL-6 and IL-6R have been reported in several chronic inflammatory and autoimmune diseases as well as in cancer (44, 45, 46). However, the cytokine production levels of IL-1 $\beta$, IL-2, IL-1RA and IL-2R were not affected by the MF exposure neither in the continuous mode nor in the intermitten mode.

To date, and to our knowledge, information regarding the effects of extremely low frequency MF on human cytokines is scarce. Most studies were carried out in in vitro models. These studies on the peripheral blood mononuclear cells cultures (PBMC) have shown conflicting results. Some authors reported an increase of cytokine production such as IFN- $\gamma$ and IL-4, IL1, and IL-6 $(23,25,47)$ after exposure to ELF-MF or a decrease in TNF- $\alpha$ and IFN- $\gamma$ production (25) while others did not find any effect on IL-1 $\beta$, IL-8, IFN- $\gamma$, TNF- $\alpha$, IL-10, IL6 and IL-2 production $(24,48,47,22,49)$. This inconsistency in the results might be due to the difference in the type of the magnetic field and/or the intensities used.

In our study, the effect observed on IL-6 was obtained with intermittent and not with continuous exposure. It is to note that a similar effect in vitro (an increase of IL-6) in the literature has been reported with pulsed magnetic field (23), while no effect was found with static or continuous alternating magnetic field $(47,49)$. It is likely that the type of MF applied may be of importance and could have a different impact on the production of IL-6. Further confirmation of these findings in human subjects are desirable. 
In animal studies, only a few studies have investigated cytokine production in immune cells after exposure to ELF EMFs. Some authors have reported that exposure of sheep to EMF had no effect on the activity of IL-1 or IL-2 (50). A reduction in IL-1 activity was observed in their previous studies (51). The authors concluded that the difference observed in the results might be attributed to magnetic field strength and/or the age of the animals used which could be important variables in determining whether EMF exposure will affect IL-1 activity. Another study has reported that exposure to $1 \mathrm{mT}$ ELF-MF increased IL-1 $\beta$ at transcriptional and translational level in rat cortical neurons (52). IL-1 $\beta$ release was also reported to increase in macrophages after $24 \mathrm{~h}$ exposure to $1 \mathrm{mT}$ of $50 \mathrm{~Hz} \mathrm{MF}(53)$

\section{Conclusions:}

The results obtained for IL-6 in the present study should be interpreted with caution and require further studies and confirmation to ascertain if the effect observed is due to $\mathrm{MF}$ exposure and reproducible. It is also important to stress the potential clinical significance of this increase of IL-6 concentration particularly since its receptor (IL-6R) had been found to be increased under exposure to MF (54).

Overall, the lack of effect observed in the present study on IL-1beta, IL-2, IL-1RA and IL-2R supports our previous findings in which acute exposure (9 hours) to 50-Hz magnetic fields (10 $\mu \mathrm{T}$ ) did not affect the immunologic and hematologic systems (19), melatonin secretion (26), hormones of the hypothalamo-pituitary-thyroid and adrenal axis (55), and a large number of clinical chemistry variables (56) including biogenic amines (57). Even our chronic study on workers exposed daily to magnetic fields for a period of 1-20 $\mathrm{yr}$ in their workplace and at home showed that this exposure does not lead to alterations in the melatonin secretion (58). 


\section{Acknowledgements}

We wish to thank the engineers from EDF for their precious help. This study was supported by a grant from le Ministère de l'Environnement (Ministry of the environment) and from Electricité de France (EDF).

\section{References}

1. Wertheimer N, Leeper E. Electrical wiring configurations and childhood cancer. Am J Epidemiol. 109(3): 273-284, 1979

2. Demers PA, Thomas DB, Rosenblatt KA, Jimenez LM, McTiernan A, Stalsberg H, Stemhagen A, Thompson WD, Curnen MG, Satariano W, Austin DF, Isacson P, Greenberg RS, Key C, Kolonel LN and West DW. Occupational exposure to electromagnetic fields and breast cancer in men. Am J Epidemiol. 134(4): 340-347, 1991

3. Olsen JH, Nielsen A, Schulgen G. Residence near high voltage facilities and risk of cancer in children. BMJ. 307(6909): 891-895, 1993

4. Savitz DA, and Loomis DP. Magnetic field exposure in relation to leukemia and brain cancer mortality among electric utility workers. Am J Epidemiol. 141(2): 123-34. Erratum in: Am J Epidemiol. 1996. 144(2): 205, 1995

5. Kheifets LI, Afifi AA, Buffler PA, Zhang ZW. Occupational electric and magnetic field exposure and brain cancer: a meta-analysis. J Occup Environ Med. 37(12): 13271341,1995

6. Fear NT, Simpson J, and Roman E. United Kingdom Childhood Cancer Study Investigators. Childhood cancer and social contact: the role of paternal occupation (United Kingdom). Cancer Causes Control. 16(9): 1091-1097, 2005 
7. Miller AB, To T, Agnew DA, Wall C, and Green LM. Leukemia following occupational exposure to $60-\mathrm{Hz}$ electric and magnetic fields among Ontario electric utility workers. Am J Epidemiol. 144(2): 150-160, 1996

8. Coogan PF, Clapp RW, Newcomb PA, Wenzl TB, Bogdan G, Mittendorf R, Baron JA, and Longnecker MP. Occupational exposure to 60-hertz magnetic fields and risk of breast cancer in women. Epidemiology. 7(5): 459-464, 1996

9. Thériault G, Li CY. Risks of leukaemia among residents close to high voltage transmission electric lines. Occup Environ Med. 54(9): 625-628, 1997

10. McBride ML, Gallagher RP, Theriault G, Armstrong BG, Tamaro S, Spinelli JJ, Deadman JE, Fincham B, Robson D, Chaoi W. Power-frequency electric and magnetic fields and risk of childhood leukemia in Canada. Am J Epidemiol. 149: 831-842, 1999

11. IARC: Non ionizing radiation, PART 1: Static and Extremely Low Frequency (ELF) Electric and Magnetic Field. Vol. 80, IARC Monographs on the evaluation of carcinogenic Risks to humans, International Agency for Research on Cancer, Lyon, 2002.

12. McLean JR, Stuchly MA, Mitchel RE, Wilkinson D, Yang H, Goddard M, Lecuyer DW, Schunk M, Callary E, and Morrison D. Cancer promotion in a mouse-skin model by a $60-\mathrm{Hz}$ magnetic field: II. Tumor development and immune response. Bioelectromagnetics. 12(5): 273-287, 1991

13. Tremblay L, Houde M, Mercier G, Gagnon J, Mandeville R. Differential modulation of natural and adaptive immunity in Fischer rats exposed for 6 weeks to $60 \mathrm{~Hz}$ linear sinusoidal continuous-wave magnetic fields. Bioelectromagnetics. 17: 373-383, 1996

14. House RV, Ratajczak HV, Gauger JR, Johnson TR, Thomas PT, McCormick DL. Immune function and host defense in rodents exposed to $60-\mathrm{Hz}$ magnetic fields. Fund Appl Toxicol. 34: 228-239, 1996 
15. House RV and McCormick DL. Modulation of natural killer cell function after exposure to $60 \mathrm{~Hz}$ magnetic fields: Confirmation of the effect in mature B6C3F1 mice. Radiat. Res 153: 722-724, 2000

16. Bonhomme-Faivre L, Marion S, Forestier F, Santini R, and Auclair H. Effects of electromagnetic fields on the immune systems of occupationally exposed humans and mice. Arch Environ Health. 58: 712-717, 2003

17. Gobba F, Bargellini A, Scaringi M, Bravo G, and Borella P. Extremely low frequencymagnetic fields (ELF-EMF) occupational exposure and natural killer activity in peripheral blood lymphocytes. Sci Total Environ. 407(3): 1218-1223, 2009

18. Ramoni C, Dupuis ML, Vecchia P, Polichetti A, Petrini C, Bersani F, Carri M, Cossarizza A, Franceschi C, Grandolfo M. Human natural killer cytotoxic activity is not affected by in vitro exposure to $50-\mathrm{Hz}$ sinusoidal magnetic fields. Int $J$ Radiat Biol. 68: 693-705, 1995

19. Selmaoui, B, Bogdan A, Auzeby A, Lambrozo J and Touitou Y. Acute exposure to 50$\mathrm{Hz}$ magnetic field does not affect haematological and immune functions in young healthy men. A circadian study. Bioelectromagnetics. 17: 364-372, 1996

20. Thun-Battersby S, Westermann $\mathrm{J}$ and Loscher W. Lymphocyte subset analyses in blood, spleen and lymph nodes of female Sprague-Dawley rats after short or prolonged exposure to a $50 \mathrm{~Hz} 100$ microT magnetic field, Radiat Res 152: 436-443, 1999 
21. Graham C, Sastre A, Cook MR and Gerkovich MM. All-night exposure to EMF does not alter urinary melatonin, 6-OHMS or immune measures in older men and women. $J$ Pineal Res 31(2): 109-113, 2001

22. Ikeda K, Shinmura Y, Mizoe H, Yoshizawa H, Yoshida A, Kanao S, Sumitani H, Hasebe S, Motomura T, Yamakawa T, Mizuno F, Otaka Y, Hirose H. No effects of extremely low frequency magnetic fields found on cytotoxic activities and cytokine production of human peripheral blood mononuclear cells in vitro. Bioelectromagnetics. 24(1): 21-31, 2003

23. Cossarizza A, Angioni S, Petraglia F, Genezzani AR, Monti D, Capri M, Bersani F, Cadossi R and Franceschi C. Exposure to low frequency pulsed electromagnetic fields increases interleukin-1 and interleukin-6 production by Human peripheral blood mononuclear cells. Experimental Cell Research. 204(2): 385-387, 1993

24. Petrini C, Dupuis ML, Polichetti A, Ramoni C, Vecchia P. Tumor necrosis factor a and interferon g production by human peripheral blood mononuclear cells exposed in vitro to sinusoidal $50 \mathrm{~Hz}$ magnetic fields. Bioelectrochem Bioenerg. 44: 121-125, 1997

25. Jonai H, Villanueva MB, Yasuda A. Cytokine profile of human peripheral blood mononuclear cells exposed to $50 \mathrm{~Hz}$ EMF. Ind Health. 34: 359-368, 1996

26. Selmaoui B, Lambrozo J and Touitou Y. Magnetic fields and pineal function in human: Evaluation of nocturnal acute exposure to extremely low frequency magnetic fields on serum melatonin and urinary 6-sulfatoxymelatonin circadian rhythms. Life Sciences. 58: 1539-1549, 1996

27. Greenland S, Sheppard AR, Kaune WT, Poole C, Kelsh MA. A pooled analysis of magnetic fields, wire codes, and childhood leukemia. Childhood Leukemia-EMF Study Group. Epidemiology. 11(6):624-634, 2000 
28. Ahlbom A, Day N, Feychting M, Roman E, Skinner J, Dockerty J, Linet M, McBride M, Michaelis J, Olsen JH, Tynes T, and Verkasalo PK. A pooled analysis of magnetic fields and childhood leukaemia. Br J Cancer. 83(5): 692-698, 2000

29. Swanson J and Kheifets L. Biophysical mechanisms: a component in the weight of evidence for health effects of power-frequency electric and magnetic fields. Radiation Res. 165: 470-478, 2006

30. Perry MG, Kirwan JR, Jessop DS, Hunt LP. Overnight variations in cortisol, interleukin-6, tumor necrosis factor alpha and other cytokines in people rheumatoid arthritis. Ann. Rheum. Dis. 68(1): 63-68, 2009

31. Jawa RS, Anillo S, Huntoon K, Baumann H, Kulaylat M. Analytic review: interleukin-6 in surgery, trauma, and critical care: part I: basic science. J. Intensive Care Med. 26(1): 3-12, 2011

32. Mastorakus G. and Ilias I. Interleukin-6: a cytokine and/or a major modulator of the response to somatic stress. Ann. NY Acad. Sci. 1088: 373-381, 2006

33. Spooren A, Kolmus K, Laureys G, Clinckers R, De Keyser J, Haegeman G, Gerlo S. Interleukin-6, a mental cytokine. Brain Res. Rev. [Epub ahead of print], 2011

34. Kristiansen OP and Mandrup-Poulsen T. Interleukin-6 and diabetes: the good, the bad, or the indifferent? Diabetes 54(Suppl 2): S114-S124, 2005

35. Dubiński A. and Zdrojewicz Z. [The role of interleukin-6 in development and progression of atherosclerosis] (in Polish). Pol. Merkur. Lekarski 22(130): 291-294, 2007

36. Dowlati Y, Herrmann N, Swardfager W, Liu H, Sham L, Reim EK, Lanctot KL. A meta-analysis of cytokines in major depression. Biological Psychiatry 67(5): 445-457, 2010 
37. Tackey E, Lipsky PE, Illei GG. Rationale for interleukin-6 blockade in systemic lupus erythematosus. Lupus 13(5): 339-343 2004

38. Nishimoto N. Interleukin-6 in rheumatoid arthritis. Curr. Opin. Rheumatol. 18(3): 277-281, 2006

39. Patel AM and Moreland LW. Interleukin-6 inhibition for treatment of rheumatoid arthritis: a review of tocilizumab therapy. Drug Des. Devel. Ther. 4: 263-278, 2010

40. Smith PC, Hobisch A, Lin DL, Culig Z, Keller ET. Interleukin-6 and prostate cancer progression. Cytokine Growth Factor Rev. 12(1): 33-40, 2001

41. Am Soc Clin Oncol. Cancer Patients typically have increased interleukin-6 levels. Am Soc Clin Oncol 2006 Annual Meeting. Abstracts 8632 and 8633, 2006

42. Berger FG. The interleukin-6 gene : a susceptibility factor that may contribute to racial and ethnic disparities in breast cancer mortality. Breast Cancer Res. Treat. 88(3): 281-285, 2005

43. Barton BE. Interleukin- 6 and new strategies for the treatment of cancer, hyperproliferative diseases and paraneoplastic syndromes. Expert Opin. Ther. Targets 9(4): 737-752, 2005

44. Rose-John S, Waetzig GH, Scheller J, Grötzinger J, Seegert D. The IL-6/sIL-6R complex as a novel target for therapeutic approaches. Expert Opin Ther Targets. 11(5): 613-624, 2007

45. Scheller J, and Rose-John S. Interleukin-6 and its receptor: from bench to bedside. Med. Microbiol. Immunol. 195(4): 173-183, 2006

46. Barillé S, Bataille R, and Amiot M. The role of interleukin-6 and interleukin6/interleukin-6 receptor-alpha complex in the pathogenesis of multiple myeloma. Eur Cytokine Netw. 11(4): 546-551, 2000 
47. Salerno S, Lo Casto A, Caccamo N, d'Anna C, de Maria M, Lagalla R, Scola L, Cardinale AE. Static magnetic fields generated by a $0.5 \mathrm{~T}$ MRI unit affects in vitro expression of activation markers and interleukin release in human peripheral blood mononuclear cells (PBMC). Int J Radiat Biol. 75(4): 457-463, 1999

48. Pessina GP and Aldinucci C. Pulsed electromagnetic fields enhance the induction of cytokines by peripheral blood mononuclear cells challenged with phytohemagglutinin. Bioelectromagnetics. 19(8): 445-451, 1998

49. Kleijn SD, Bouwens M, Verburg-van Kemenade BM, Cuppen JJ, Ferwerda G, Hermans PW. Extremely low frequency electromagnetic field exposure does not modulate toll-like receptor signaling in human peripheral blood mononuclear cells. Cytokine. doi:10.1016/j.cyto.2010.12.016, 2011

50. Hefeneider SH, McCoy SL, Hausman FA, Christensen HL, Takahashi D, Perrin N, Bracken TD, Shin KY, Hall AS. Long-term effects of $60-\mathrm{Hz}$ electric vs. magnetic fields on IL-1 and IL-2 activity in sheep. Bioelectromagnetics. 22(3): 170-177, 2001

51. Hefeneider SH. Joint HVAC Transmission EMF Environmental Study: Final Report on Experiment 3. Bonneville Power Administration, Portland, OR. 1994

52. Di Loreto S, Falone S, Caracciolo V, Sebastiani P, D'Alessandro A, Mirabilio A, Zimmitti V, Amicarelli F. Fifty hertz extremely low-frequency magnetic field exposure elicits redox and trophic response in rat-cortical neurons. J Cell Physiol. 219(2): 334-343, 2009 
53. Frahm J, Lantow M, Lupke M, Weiss DG, Simkó M. Alteration in cellular functions in mouse macrophages after exposure to $50 \mathrm{~Hz}$ magnetic fields. J Cell Biochem. 99(1): 168-177, 2006

54. Zhou J, Li C, Yao G, Chiang H, Chang Z. Gene expression of cytokine receptors in HL60 cells exposed to a $50 \mathrm{~Hz}$ magnetic field. Bioelectromagnetics. 23(5): 339-346, 2002

55. Selmaoui B, Lambrozo J. and Touitou Y. Endocrine functions in humans exposed to 50-Hz magnetic field. A circadian study of pituitary, thyroid and adrenal hormones. Life Sciences. 61: 473-486, 1997

56. Selmaoui B, Lambrozo J. and Touitou Y. Assessment of nocturnal exposure to 50-Hz magnetic fields on the human circadian system. A comprehensive study of biochemical variables. Chronobiol Int. 16(6): 789-781, 1999

57. Selmaoui B, Aymard N, Lambrozo J, Touitou Y. Evaluation of the nocturnal levels of urinary biogenic amines in men exposed overnight to magnetic field. Life Sciences. 73 (24): 3073-3082, 2003

58. Touitou Y, Lambrozo J, Camus F, Charbuy H. Magnetic fields and the melatonin hypothesis: a study of workers chronically exposed to $50-\mathrm{Hz}$ magnetic fields. $A m J$ Physiol Regul Integr Comp Physiol. 284(6):R1529-1535, 2003 
Table I. Coefficients of variation for low and high controls for the measured variables

\begin{tabular}{|c|c|c|c|c|c|c|c|}
\hline \multirow{2}{*}{ Variables } & \multirow{2}{*}{ Units } & \multicolumn{3}{|c|}{ Control I (Low values) } & \multicolumn{3}{|c|}{ Control II (High values) } \\
\hline & & Range & Mean & $\mathrm{CV}$ & Range & Mean & $\mathrm{CV}$ \\
\hline Interleukin-1 Beta & $\mathrm{pg} / \mathrm{ml}$ & $79-129$ & 105.3 & $9.7 \%$ & $380-580$ & 514.5 & $9.8 \%$ \\
\hline $\begin{array}{l}\text { Interleukin-1 RA } \\
\text { [Receptor Antagonist] }\end{array}$ & $\mathrm{pg} / \mathrm{ml}$ & $66.7-73.7$ & 72.5 & $19.0 \%$ & $534.8-591.2$ & 547.1 & $5.4 \%$ \\
\hline Interleukin-2 & $\mathrm{U} / \mathrm{ml}$ & $3.9-6.5$ & 5.0 & $17.6 \%$ & $10.0-15.0$ & 14.2 & $11.6 \%$ \\
\hline $\begin{array}{l}\text { Interleukin-2R } \\
\text { [Receptor] }\end{array}$ & $\mathrm{pg} / \mathrm{ml}$ & $1002-1502$ & 1247.7 & $9.4 \%$ & $3187-4781$ & 3784.8 & $17.5 \%$ \\
\hline Interleukin-6 & $\mathrm{pg} / \mathrm{ml}$ & $91-137$ & 120.9 & $8.2 \%$ & $200-300$ & 297.1 & $4.7 \%$ \\
\hline
\end{tabular}


Table II: Repeated-measures 2-way ANOVA: comparison between exposed and sham exposed by examining the main effects of the field (continuous or intermittent), the time factor and their interaction.

\section{IL-6}

Field

0.2878

0.0186

Time

0.1156

$<0.0001$

Field X Time interaction

0.5635

0.0032

\section{IL-1RA}

Field

0.5198

0.3455

Time

0.0012

0.0042

Field $X$ Time interaction

0.7975

0.3022

\section{IL-1 Beta}

Field

0.5556

0.6382

Time

0.7566

0.6379

Field $\mathrm{X}$ Time interaction

0.2267

0.4402

\section{IL-2}

Field

0.7220

0.3851

Time

0.0962

0.5906

Field $X$ Time interaction

0.5663

0.1425

\section{IL-2R}

Field

0.0768

0.1441

Time

0.0584

$<0.0001$

Field $\mathrm{X}$ Time interaction

0.9721

0.9587 